\title{
Supplier selection by Using AHP-TOPSIS and Goal Programming - A case Study in Casumina Rubber Company - Vietnam
}

\author{
Ha Thi Xuan Chi ${ }^{\mathrm{a}}$, Do Hoang Ngoc Trinh \\ International University - Vietnam National University-HCMC, Vietnam
}

\begin{abstract}
Suppliers, one of the important factors, directly affect to trade strategy of a company which frequently changed. Evaluating the supplier's abilities is a required step to select the appropriate supplier who ensure meet the demands of the company flexibly. This paper integrates both MADM and MODM approaches considering quantitative and qualitative techniques to support decision makers select the best solution under criteria and goals suggested by the company in different period. Analytic Hierarchy Process (AHP) and Technique for Order Preference by Similarity to Ideal Solution method (TOPSIS) are used to weigh criteria and obtain total score for each alternative, respectively. In addition, Goal Programming (GP) allows defining priorities of goals and conflicted goals as the company expects to achieve. This study combines three methods solving the supplier section issue for Casumina Rubber Company in Vietnam.
\end{abstract}

\section{Introduction}

Purchasing management is an essential part that constitutes to a successful business. According the study done by Ghodsypour and O'brien [1], the cost of raw materials and resources can account up to $70 \%$ of final cost price. Therefore, the company can manage to select the supplier based on the lowest possible cost; it can result in a significant reduction in final products price and increase profit gained. However, selecting the best suppliers not only based on the lowest price that offers from suppliers, but regard to other factors such as quality, durability, delivery, cost. Thomas Saaty [2] firstly introduced a well-known method named Analytic Hierarchy Process (AHP) to help solving complex problems and conflicting criteria in decision making. AHP allows building the hierarchy tree including level of goals, criteria, sub-criteria and alternatives. In practice, many companies have successfully selected the best supplier by applying AHP. In general, AHP, a great support tool, is widely applied in many different fields; for instance, in manufacturing system, in layout design, in supplier selection. However, AHP suffers from number of items in each level no more than nine. Thus, AHP is unable to deal with complicated situations. In order to overcome this shortcoming, TOPSIS, as an effective tool for making multi-criteria and introduced first by Hwang and Yoonc[3]. TOPIS method has been successfully applied by Omid Jadidi, Fatemeh Firouzu, Enzo Bagliery for supplier selection [4]; Vijay Manikrao Athawale, Shakar Chakraborty [5] for machine tool selection ; Amir Naderi, Mohanmad Saeed Zaeri [6] for evaluation suppliers in supply chain management; Birsen Karpak,
Rammohan E. Kasuganti [7] for an application of visual interactive goal programming. Moreover, the combination of AHP-TOPSIS brings useful outcome for business in case of $\mathrm{Min} \mathrm{Wu}$ [8] proposed simulation model and its application to supply chain management; Jayaram C Sasi, Dr, Abhijeet K Digalwar [9] offered solution for supplier selection between India \& China in Textile Industry.

Multi-criteria decision-making (MCDM) is divided into two subtypes named Multi-Objective Decision Making (MODM) and Multi-Attribute Decision Making (MADM). MODM can determine the optimal solution for both single objective and multiple objectives under satisfying the constraints and preferences priorities. Methods can be considered as MODM are Linear Programming (LP), Goal Programming (GP), Mix Integer Programming (MIG), Data Envelopment Analysis (DEA). Unlike MODM, MADM limits a number of predetermined alternatives; numerous methods for solving decision-making problems are AHP, TOPSIS, ANP, MAUT, Outranking and others. Therefore, a perfectly combination between MADM and MODM for evaluating performance of suppliers are necessary. Indeed, there are many researches highlight integration of several methods that their advantages can be utilized. Ghodsypour, S.H., O'Brien [1] used an integrated analytical hierarchy process and linear programming for supplier selection. Sanayei, A., Mousavi, S.F Abdi, M.R and Mohaghar, A.,[10] used an integrated group decision making process for supplier selection and order allocation using muli -attribute utility theory and linear programming ; Razmi, L., Rafiei, H. [11], proposed “An intergrated analytic network process with mixed- integer

\footnotetext{
${ }^{\mathrm{a}}$ Corresponding author: htxchi@hcmiu.edu.vn
} 
Non-linear Programming to supplier selction and order allocation. Weber, C.A., Ellram, L.M. [10] used multiobjective programming: a decision support system approach for supplier selection. Therefore, this paper employs AHP, TOPSIS and GP to solve selection supplier for the Casumina rubber company.

This paper is organized as follows. Section 1 presents introduction. Section 2 shows reviewing existing methods. A case study are described in Section 3. In Section 4, the results of the case study are displayed. The rest is conclusion.

\section{Reviewing existing methods}

In this section, three main relevant methods have been considered. Firstly, AHP is used to simply obtain the weight of each criterion. Secondly, total scores of alternatives are gained by using TOPSIS. Finally, GP model shows the priorities, conflicting goals of the company that allow evaluating suppliers appropriately.

\subsection{AHP method}

As being released the first time by Thomas Saaty in 1980, The Analytic Hierarchy Process (AHP) is widely known for its power for being used as a helpful tool to solve the matter of complex decision making. It possesses the advantages in evaluating and selecting the best solution among alternative solutions, based on list of criteria. AHP procedure has been presented as the following steps:

Step 1: Constructing the decision hierarchy

Step 2: Constructing the pair wise comparison matrix

$$
A_{n \times n}=\begin{gathered}
A_{1} \\
A_{2} \\
\vdots \\
A_{n}
\end{gathered}\left[\begin{array}{cccc}
1 & a_{12} & \ldots & a_{1 n} \\
1 / a_{12} & 1 & \ldots & a_{2 n} \\
\vdots & \vdots & \vdots & \vdots \\
1 / a_{1 n} & 1 / a_{2 n} & \ldots & 1
\end{array}\right]
$$

Step 3: Constructing normalized decision matrix

$$
c_{i j}=a_{i j} / \sum_{j=1}^{n} a_{i j}
$$

With $i=1,2,3 \ldots n, j=1,2,3 \ldots n$

Step 4: Constructing the weighted, normalized decision matrix

$$
w_{i}=\sum_{j=1}^{n} c_{i j} / n
$$

Step 5: Calculating Eigenvector and Row matrix

$$
\begin{gathered}
E=N^{\text {th }} \text { roothvalue } / \sum N^{\text {th }} \text { roothvalue } \\
\text { Row matrix }=\sum_{j=1}^{n} a_{i j} * e_{j 1}
\end{gathered}
$$

Step 6: Calculating the maximum Eigenvalue, $\lambda_{\max }$

$$
\lambda_{\max }=\text { Row matrix } / E
$$

Step 7: Calculating the consistency index and consistency ratio

Consistency index

$$
\mathrm{CI}=\left(\lambda_{\max }-\mathrm{n}\right) /(\mathrm{n}-1)
$$

Consistency Ratio

$$
C R=C I / R I
$$

\subsection{TOPSIS method}

Yoon and Hwang firstly invented TOPSIS (Technique for Order Preference by Similarity to Ideal Solution) method. It is well-known as useful tool to aid in decision making. The basic idea of this technique is choosing the alternative should have a shortest distance from the ideal solution and farthest distance from the negative distance. TOPSIS is presented as follows:

Step 1: The structure of matrix

$$
D=\left[\begin{array}{ccccc} 
& X_{1} & X_{2} & \ldots & X j \\
A_{1} & X_{11} & X_{12} & \ldots & X_{1 j} \\
A_{2} & X_{21} & X_{22} & \ldots & X_{2 j} \\
\dot{A_{i}} & X_{i 1} & X_{i 2} & \ldots & X_{i j}
\end{array}\right]
$$

Step 2: Calculate the Normalized the matrix D by using the following formula

$$
r_{i j}=x_{i j} / \sqrt{\sum_{j=1}^{J} x i j^{2}}
$$

Step 3: Construct the weighted normalized decision matrix by multiplying the normalized decision matrix by its associated weights

$$
v_{i j}=w_{i j} r_{i j}
$$

Step 4: Determine the positive ideal solution and negative ideal solution

$$
\begin{aligned}
\mathrm{A}^{*} & =\left\{\left(\max v_{i j} \mid j \in J\right),\left(\min v_{i j} \mid j \in J^{\prime}\right)\right\} \\
A^{-} & =\left\{\left(\min v_{i j} \mid j \in J\right),\left(\max v_{i j} \mid j \in J^{\prime}\right)\right\}
\end{aligned}
$$

Step 5: Calculate the separation measure

$$
\begin{gathered}
S_{i}^{*}=\sqrt{\sum_{j=1}^{n}\left(v_{i j}-v_{j}^{*}\right)^{2}} \\
S_{i}^{-}=\sqrt{\sum_{j=1}^{n}\left(v_{i j}-v_{j}^{-}\right)^{2}}
\end{gathered}
$$

Step 6: Calculate the relative closeness to the ideal solution

$$
C_{i}^{*}=S_{i}^{-} / S_{i}^{*}+S_{i}^{-}, 0 \leq C_{i}^{*} \leq 1
$$

Step 7: Calculate the total score

\subsection{Goal programming}

After getting total scores of the alternatives, a mathematical model for allocating the right quantities to be purchased from each supplier is built. In goal programming these goal are set as a target in GP, the lower priority goals are considered only after higher priority goals have been satisfied. In addition, GP also shows the flexibility in changing the priorities result in reaching the company's targets. 


\section{A case study}

In this part, the Casumina rubber company, a big manufacturer, produces many types of tire for vehicles in Vietnam. They need huge quantity raw material that ensures to meet their demands, selecting the right suppliers in order to production happen smoothly is essential. In recent, the company considers 15 suppliers (S1, S2, S3... S15) supplying two type of raw materials (SVR10 and SVR20). To evaluate these suppliers, the company bases on 6 criteria such as quality (X1), delivery (X2), profile (X3), service (X4), distance (X5), price (X6) collected from a group of 5 experts in the company shown in Table 1.

Table 1. Supplier selection criteria.

\begin{tabular}{|l|l|}
\hline Main criteria & Sub-criteria \\
\hline Quality & \\
\hline Delivery & 1. On-time \\
\cline { 2 - 2 } & 2. Right quantity \\
\hline Profile & 3. Certification ISO 9000 \\
\cline { 2 - 2 } & \begin{tabular}{l} 
4. Long term relationship \\
\cline { 2 - 2 }
\end{tabular} \\
\cline { 2 - 2 } & $\begin{array}{l}\text { 5. Reputation and position in } \\
\text { industry }\end{array}$ \\
\hline Service & 6. Flexible \\
\cline { 2 - 2 } & 7. After sale service \\
\hline Distance & \\
\hline Price & \\
\hline
\end{tabular}

The average weight of criteria is obtained from the group decision maker for item $1: X 1=0.44, X 2=0.12$, $X 3=0.09, X 4=0.05, X 5=0.03, X 6=0.27$

The average weight of criteria is obtained from the group decision maker for item $2: X 1=0.45, X 2=0.12$, $X 3=0.08, X 4=0.05, X 5=0.03, X 6=0.26$.

Then inputting these weighted into TOPSIS, result for item 1 and item 2:

$\mathrm{C}_{1}^{*}=0.22, \mathrm{C}_{2}^{*}=0.21, \mathrm{C}_{3}^{*}=0.23, \mathrm{C}_{4}^{*}=0.33, \mathrm{C}_{5}^{*}=$ $0.32, \mathrm{C}_{6}^{*}=0.53, \mathrm{C}_{7}^{*}=0.21, \mathrm{C}_{8}^{*}=0.39, \mathrm{C}_{9}^{*}=0.25, \mathrm{C}_{10}^{*}=$ $0.14, \mathrm{C}_{11}^{*}=0.22, \mathrm{C}_{12}^{*}=0.50, \mathrm{C}_{13}^{*}=0.27, \mathrm{C}_{14}^{*}=$ $0.27, \mathrm{C}_{15}^{*}=0.33$.

$\mathrm{C}_{1}^{*}=0.19, \mathrm{C}_{2}^{*}=0.16, \mathrm{C}_{3}^{*}=0.22, \mathrm{C}_{4}^{*}=0.37, \mathrm{C}_{5}^{*}=$ $0.38, \mathrm{C}_{6}^{*}=0.49, \mathrm{C}_{7}^{*}=0.29, \mathrm{C}_{8}^{*}=0.28, \mathrm{C}_{9}^{*}=0.23, \mathrm{C}_{10}^{*}=$ $0.24, \mathrm{C}_{11}^{*}=0.21, \mathrm{C}_{12}^{*}=0.41, \mathrm{C}_{13}^{*}=0.28, \mathrm{C}_{14}^{*}=$ $0.24, \mathrm{C}_{15}^{*}=0.33$.

Then, total weighted score from TOPSIS are used as one of the goals in GP model.

\subsection{Indices}

$i$ : index of item $i=1,2, \ldots i$;

$j$ : index of supplier $j=1,2, \ldots, j$;

\subsection{Parameters}

$q_{i j}$ : Defects ratio of item i from supplier $\mathrm{j}$ in period $\mathrm{t}(\%)$ $d_{i j}$ : Delivery delay of item i from supplier $\mathrm{j}$ (days)

$D_{i t}$ : Total demand for item $\mathrm{i}$ in the period $\mathrm{t}$ (ton)
$P_{i j t}:$ Unit price of ordered item i from supplier $\mathrm{j}$ in period $\mathrm{t}$ (\$/ton)

$T S_{i j}$ : Total score of supplier $\mathrm{j}$ for item $\mathrm{i}$ from TOPSIS

$\Delta_{i j}$ : Flexible level of supplier j supplying i item

$N$ : Minimum number of selected suppliers supplying item $\mathrm{i}$

$B_{i t}$ : Total budget for purchasing item $\mathrm{i}$ in period $\mathrm{t}$

$Q_{i j \text { min }}:$ Minimum order quantity of item i from supplier $\mathrm{j}$ in the period $\mathrm{t}$

$Q_{i j \text { max }}$ : Maximize order quantity of item i from supplier $\mathrm{j}$ in the period $\mathrm{t}$

PC: purchasing cost $(\$)$

DT: delivery time (days)

DE: defective amount (\%)

CA: level of capacity (\%)

I: ideal total weighted score

$d_{k}^{+}$: Amount of deviation above the goal

$d_{k}^{-}$: Amount of deviation below the goal

3.4 Decision variables:

$X_{i j t}$ : Order quantity item $\mathrm{i}$ from supplier $\mathrm{j}$ in period $\mathrm{t}$

$Y_{i j}$ : Binary variable if the $j^{\text {th }}$ supplier supplying item $\mathrm{i}$ is selected or not

$Y_{i j}=\left\{\begin{array}{l}1: \text { if } X i j>0 \\ 0: \text { otherwise }\end{array}\right.$

$d_{k}^{+} \geq 0, \mathrm{k}=1,2,3,4,5$

$d_{k}^{-} \geq 0, \mathrm{k}=1,2,3,4,5$

\subsection{Mathematical model}

Objective functions:

$$
Z=\min \left\{d_{1}^{-}+d_{2}^{+}+d_{3}^{+}+d_{4}^{-}+d_{5}^{-}\right\}
$$

Goal constraints:

Maximize the total weighted value of purchase:

$$
\sum_{t} \sum_{i} \sum_{j} T S_{i j} * X_{i j t}+d_{1}^{-}-d_{1}^{+}=I
$$

In this constraint we use the scores obtained from TOPSIS technique. Thus, the purpose of this constraint is to try to allocate more unit order to the supplier with the higher total scores in the period of time.

Minimize total cost of purchasing:

$$
\sum_{t} \sum_{i} \sum_{j} P_{i j t} * X_{i j t}+d_{2}^{-}-d_{2}^{+}=P C
$$

Purchasing cost account for $70 \%$ of complete product value so one of the most important duty for purchasing department is try to minimize the cost as much as possible. This constraint is minimizing the expense in the period $t$ by the total cost offered by each supplier and the orders that company placed.

Minimize the average delivery time delay:

$$
\sum_{i} \sum_{j} d_{i j} * Y_{i j}+d_{3}^{-}-d_{3}^{+}=D T
$$

Delivery delay may cause the bad influence to company such as manufacturing slackness as well as the supplier's prestige. Thus, this constraint is expected to minimize the delivery time delay for each supplier.

Minimize the average defect ratio:

$$
\sum_{t} \sum_{i} \sum_{j} q_{i j} * X_{i j t}+d_{4}^{-}-d_{4}^{+}=D E
$$


This constraint is tried to minimize the defective ratio by collecting the defective percentage rate of each supplier for item $\mathrm{i}$ and orders that company placed Maximize the supplier's capacity flexibility:

$$
Y_{i j}+d_{5}^{-}-d_{5}^{+}=C A
$$

Each supplier has their own capacity. However, the company expects that whenever they need, supplier can satisfy the demand. Thus, this constraint is maximized the supplier's capacity flexibility by total the percentage level flexible and order that company placed.

Hard constraints:

Minimum order quantity:

$$
X_{i j t} \geq Q_{i j t \min } * Y_{i j}, \forall i, j
$$

This constraint is the orders that company placed in period $t$ should larger than the minimum order quantity of item $i$ from supplier $j$ in the period time $t$.

Maximum order quantity:

$$
X_{i j t} \leq Q_{i j t \max } * Y_{i j}, \forall i, j
$$

This constraint is the orders that company placed in period $t$ should less than the maximum order quantity of item $i$ from supplier $j$ in the period $t$.

Production demand:

$$
\sum_{j} X_{i j t} *\left(1-q_{i j}\right) \geq D_{i t}, \forall i
$$

The amount of items no defective after production in the period $t$ should larger than the demand for order item in period $t$.

Minimum number of suppliers:

$$
\sum_{j} Y_{i j} \geq N, \forall i
$$

The minimum number of selected suppliers supplying item $i$ should less than number of supplier selected.

Purchasing budget:

$$
\sum_{j} P_{i j t} * X_{i j t} \leq B_{i t}
$$

The cost for buying material in the period time $t$ should be less than the budget that company have for purchasing item $i$ in period $\mathrm{t}$

$$
X_{i j t}>=0 \text { and integer } \forall i, j
$$

Binary constraints:

$$
Y_{i j}=0 \text { or } 1 \forall i, j
$$

\subsection{Data collection}

The strategy of company is shown as follows:

- There are four quarter period per year.

- Two raw materials SVR10 and SVR20 are considered.

- Purchasing cost that company spends for material in year is $\$ 998000$.

- Delivery time days that company is allow for each supplier to be late is 3 days.

- Defective amount is to be expected in $8 \%$

- Flexible level capacity that company expect supplier is $10 \%$.

- $\quad$ Total weighted scored is 95 .

\section{Results}

\subsection{Goal achievement}

In this section, this study shows goal achievement based on goal priority of the company. As shown in Table 2, the both objectives total weighted value and purchasing cost are achieved with $\mathrm{d}_{1}^{-}=0$ and $\mathrm{d}_{2}^{+}=0$, the rest of objectives cannot reach the goals with $\mathrm{d}_{3}^{+}=3, \mathrm{~d}_{4}^{+}=1.067$, and $\mathrm{d}_{5}^{-}=55$. In other words, the third, fourth, fifth goals are sacrificed in order to satisfy the first and the second goal of the company's priorities.

With goal achievement result, Table 3 displays the detailed results of five goals corresponding with each supplier that supports decision makers make a right

\begin{tabular}{|c|c|c|c|c|c|}
\hline Suppliers & I & PC(\$) & DE (\%) & DT(days) & $\begin{array}{l}\text { CA } \\
(\%) \\
\end{array}$ \\
\hline 1 & 113.1 & 83190.3 & 6.4 & 3 & 13 \\
\hline 2 & 110.3 & 85765 & 7.2 & 2 & 11 \\
\hline 3 & 127.6 & 84656.2 & 7.3 & 3 & 5 \\
\hline 4 & 97.0 & 43568 & 2.9 & 3 & 4 \\
\hline 5 & 163.3 & 69258 & 5.8 & 3 & 6 \\
\hline 6 & 124.6 & 34901 & 2.4 & 1 & 3 \\
\hline 7 & 106.4 & 64869 & 8.0 & 4 & 6 \\
\hline 8 & 96.8 & 37199 & 3.3 & 1 & 6 \\
\hline 9 & 122.6 & 75547 & 5.6 & 5 & 10 \\
\hline 10 & 95.1 & 72904 & 9.1 & 3 & 8 \\
\hline 11 & 120.4 & 83557 & 6.1 & 3 & 3 \\
\hline 12 & 117.5 & 35047 & 3.3 & 3 & 6 \\
\hline 13 & 95.1 & 51923 & 4.1 & 3 & 5 \\
\hline 14 & 118.6 & 69678 & 6.2 & 3 & 11 \\
\hline 15 & 169.9 & 77472 & 3 & 5.7 & 3 \\
\hline Total & & 969531 & & & \\
\hline
\end{tabular}
decision and control their solution. The total weighted scores of all suppliers are greater than 95 satisfying the first priority,

Table 2. Goal achievement.

\begin{tabular}{|c|l|c|c|}
\hline Priorities & \multicolumn{1}{|c|}{ Goals } & Objectives & Results \\
\hline 1 & $\begin{array}{l}\text { Total weighted value } \\
\text { for all suppliers }\end{array}$ & Min $d_{1}^{-}$ & $d_{1}^{-}=0$ \\
\hline 2 & Purchasing cost (\$) & Min $d_{2}^{+}$ & $d_{2}^{+}=0$ \\
\hline 3 & $\begin{array}{l}\text { Delivery time delay } \\
\text { for all suppliers } \\
\text { (days) }\end{array}$ & Min $d_{3}^{+}$ & $d_{3}^{+}=3$ \\
\hline 4 & $\begin{array}{l}\text { Defect ratio for all } \\
\text { suppliers (\%) }\end{array}$ & Min $d_{4}^{+}$ & $d_{4}^{+}=1.067$ \\
\hline 5 & $\begin{array}{l}\text { Capacity flexibility } \\
\text { for all suppliers (\%) }\end{array}$ & Min $d_{5}^{-}$ & $d_{5}^{-}=55$ \\
\hline
\end{tabular}

Table 3. Results of total weighted value, capacity level, defective, purchasing cost. 
The company spent $\$ 998000$ to purchase two items but the results obtained from this study shows that the company only needs pay $\$ 969531$, results in saving $\$ 28469$.

\section{Conclusions}

The main purpose of the paper focuses on supplier selection problem based on three main techniques, namely Analysis Hierarchy Process (AHP), Technique for Order of Preference by Similarity to Ideal Solution (TOPSIS) and Goal Programming. Firstly, AHP is applied to determine weight for each criterion that could be quantitative or qualitative proposed by experts, and then the total weighted score for each supplier is obtained by the TOPSIS. Finally, the Goal Programming shows flexible ability by allowing decision makers establish their business strategies in different periods with certain priorities of goals.

Applying these methods, the selecting supplier problem in Casumina Company is completely solved. The results show number of goals of company can be achieved and suggest number of suppliers should be considered for purchasing. This thesis also analyze for different scenarios by changing priorities that brings decision makers more options support for their final decision.

In summary, the solution should been chosen based on company condition and the manager would make final decision to solve the present issues.

\section{References}

1. Ghodsypour, S.H. and C. O'Brien, A decision support system for supplier selection using an integrated analytic hierarchy process and linear programming. International Journal of Production Economics, (1998). 56-57: p. 199-212

2. Saaty, T.L., The Analytic Hierarchy Process: Planning, Priority Setting, Resource Allocation. (1980): McGraw-Hill
3. Hwang, C.L.Y., K. , Multiple Attribute Decision Making: Methods and Applications. (1981): New York: Springer-Verlag

4. Omid Jadidi, F.F., and Enzo Bagliery TOPSIS Method for Supplier Selection Problem World Academy of Science, Engineering and Technology, International Journal of Social, Behavioral, Educational, Economic, Business and Industrial Engineering, 4, 11 (2010).

5. Athawale, V.M., A TOPSIS method-based Approach to machine tool selection. The 2010 international coference on industriaengineering and operations management, (2010)

6. Amir Naderi, M.S.Z., Application of multi criteria decision making technique to evaluation suppliers in supply chain management. 4 (2011)

7. Birsen Karpak, R.E.K., Multi-objective decision: An application of visual interactive goal programming. The journal of applied business research. 15

8. Wu, M., Topsis-AHP simulation model and its application to supply chainmanagement. World Journal of Modelling and Simulation, (2007). 3(3): p. 196-201.

9. Jayaram C Sasi1, D.A.K.D., Application of AHP and TOPSIS Method for Supplier Selection between India \& China in Textile Industry. International Research Journal of Engineering and Technology, 2, 4 (2015)

10. Sanayei, A., et al., An integrated group decisionmaking process for supplier selection and order allocation using multi-attribute utility theory and linear programming. Journal of the Franklin Institute, (2008). 345(7): p. 731-747

11. Jafar Razmi, H.R., An integrated analytic network process with mixed-integer non-linear programming to supplier selection and order allocation. The International Journal of Advanced Manufacturing Technology, (2010). 49(9): p. 1195-1208 